\title{
Influence of concentration of sugar on mass transfer of pineapple slices during osmotic dehydration
}

\author{
S. A. A. Khanom ${ }^{1}$, M. M. Rahman ${ }^{2}$ and M. B. Uddin ${ }^{3 *}$ \\ ${ }^{1}$ Vegetable Technology Research Section, ${ }^{2}$ Enzymology Section, Institute of Food Science \& Technology, BCSIR, \\ Dhaka-1205, Bangladesh and ${ }^{3}$ Department of Food Technology and Rural Industries, Bangladesh Agricultural \\ University, Mymensigh-2202, Bangladesh, *E-mail: burhan992003@yahoo.com
}

\begin{abstract}
Osmotic drying is a partial dehydration process to give the product a quality improvement over the conventional drying process. The experiment was conducted for studying water loss(WL), sugar gain(SG), weight reduction(WR) and total solid(TS) during osmotic dehydration of pineapple slices (10 mm thick) in different concentration of sugar (40\%, $50 \%$ and $60 \%$ ) up to 6 hours at room temperature. It was found that increasing the concentration of the sugar solution used resulted in increased rates of water loss. The water loss at $40 \%$ sugar solution of pineapple slices were found to be significantly lower $(p=0.05)$ than that of at $60 \%$ sugar solution. It was found there were rapid rates of water loss, sugar gain, weight reduction for first four hour of the osmotic process.
\end{abstract}

Keywords: Pineapple slices, Sugar, Osmotic dehydration

\section{Introduction}

Pineapple (Ananas comosus) is a delicious and popular fruit of our country. It is one of the most common tropical and sub tropical fruit, consumed largely because of its attractive flavour and refreshing sugar-acid balance and a very rich source of vitamin C and organic acids (Bartolomew et al., 1995). Pineapple contains sucrose, fructose and glucose in concentration that, in combination with acids and other compounds, determine the typical flavour of this fruit (Gherardi et al., 1994). The three varieties of pineapple grown in Bangladesh are Giankew, Calendar and Juldubi. The major pineapple growing areas in Bangladesh are Madhupur, Ghorashal and Chittangong Hill tracts. Osmotic dehydration is a method for the partial dehydration of water-rich foods, such as fruits and vegetables by immersing them in a concentration of sugar and salt. It results in two simultaneous crossed flows: a water out flow, from the food to the solution and a solute inflow from the solution into the food (Hough et al., 1993: Raoult-Wack et al., 1994: Spiazzi and Mscheroni, 1997). The main problem is availability of adequate and sufficient processing technologies. Development of new technologies to process the pineapple products may promote the round year availability of pineapple and also serve the interest of the farmers.

The objectives of this study were to investigate the influence on water loss, sugar gain, weight reduction, normalised solids content during osmotic dehydration.

\section{Materials and Methods}

The experiment was conducted in the Department of Food Technology and Rural Industries, Bangladesh Agricultural University, Mymensingh. The pineapples, having $10-30 \%$ coloration from base was collected from local market. Collected samples (Ananas comosus) were washed thoroughly in clean water to remove the adhering soil and organism, outer skin were peeled manually by using knife and cut into pieces of $10 \mathrm{~mm}$ thickness. The core of the slices was also removed by using core remover.

\section{Osmotic dehydration}

The dehydration solute used was sucrose (food grade, commercial granulated cane sugar manufactured by Lenart and Flink in 1984 . Solutions of $40 \%, 50 \%$ and $60 \%(\mathrm{w} / \mathrm{w})$ sucrose concentrations were prepared by blending an amount of sucrose with distilled water on a weight to weight basis. The weight pineapple slices were dipped in different concentration of sugar. The ratio of the fruits and sugar solution was 1: 6 in order to ensure proper soaking of the samples. Samples were taken at half an hour interval up to six hours, drained quickly and wiped gently with tissue paper and analyzed for different process variables like water loss, sugar gain, weight reduction, and total solid. 


\section{Calculation of water loss}

Percent Water Loss (\%WL) was defined as the net loss of water from the fresh pineapples after osmotic dehydration based on the initial sample weight and was calculated from the following equation:

$\% W L=\frac{\left(M_{1}\right)\left(1-T_{i}\right)-\left(M_{0}\right)\left(1-T_{0}\right)}{\left(M_{1}\right)} \times 100$

\section{Calculation sugar gain}

Sugar Gain (\%SG) was defined as the net uptake of sugar by the osmosed pineapples based on the initial sample weight and was calculated by the following equation:

$$
\% S G=\frac{\left(M_{0}\right)\left(T_{0}\right)-\left(M_{i}\right)\left(T_{i}\right)}{\left(M_{i}\right)} \times 100
$$

\section{Calculation of weight reduction}

Weight Reduction (WR) was defined as the net difference in weight between the initial sample weight of the pineapples and the weight of the osmosed fruit based on the initial sample weight and was calculated by the following equation:

$$
\% W R=\frac{\left(M_{i}\right)-\left(M_{0}\right)}{M_{i}} \times 100
$$

where, $M_{i}=$ initial weight of the raw pineapples; $M_{0}=$ weight of the osmosed pineapples; $\mathrm{TS}_{\mathrm{i}}=$ initial total solids content of the raw pineapples; and $\mathrm{TS}_{0}=$ total solids content of osmosed pineapples (\% dry weight basis).

\section{Calculation of total solid}

Amount of total solids in the fruit was determined gravimetrically by vacuum oven drying at $70^{\circ} \mathrm{C}$ for 24 hours. The slices were transferred to a preweighed aluminium dish, weighed and dried in the vacuum oven. After cooling in a dessicator, the dish and the dried samples were reweighed. The percentage total solids (\% TS) was calculated as follows:

$$
\% \mathrm{TS}=\left(\frac{\mathrm{W}_{3}-\mathrm{W}_{1}}{\mathrm{~W}_{2}-\mathrm{W}_{1}}\right) \times 100
$$

where, $W_{1}=$ Weight of aluminium dish; $W_{2}=$ Weight of dish and sample; $W_{3}=$ Weight of dish and the vacuum dried samples.

\section{Results and Discussion}

\section{Influence of osmotic solution concentration on mass transfer}

The study of the influence of osmotic solution concentrations on mass transfer behavior during osmotic dehydration of pineapple slices was carried out using three different sugar solution concentrations of $40 \%$, $50 \%$ and $60 \%(\mathrm{w} / \mathrm{w})$. This experiment was carried out at temperature of $40^{\circ} \mathrm{C}$ and using of $10 \mathrm{~mm}$ pineapple slices throughout the experiment.

Fig. 1 to 4 illustrate plots of each of the respective mass transfer parameters (\% WL, \% SG, \% WR and \% TS) as a function of osmotic times due to the influence of three different sugar solution concentrations. It was observed from these figures that for all the three sugar solution concentrations $(40 \%, 50 \%$ and $60 \%)$ studied, there were rapid rates of water loss (WL), sugar gain (SG) and weight reduction (WR) for the first hour of the osmotic process, after which the rate of these mass transfer parameters gradually slowed 
down with time towards equilibrium end-point. Contreras and Smyrl (1981) as well as Lu and Brennan (1987a) have also reported rapid removal of water and uptake of solids in the early stages of the osmotic process for apples. It was also found that both sugar solution concentration and osmotic time have highly significant effects $(p=0.001)$ on values of water loss, sugar gain, weight reduction and total solids of the osmosed pineapple.

For water loss, the higher the concentration of the sugar solution used, the greater was its rate of water loss. When $40 \%$ sugar solution was used, the water loss values of the pineapple were found to be significantly lower $(p=0.05)$ than those of $60 \%$ sugar solution.

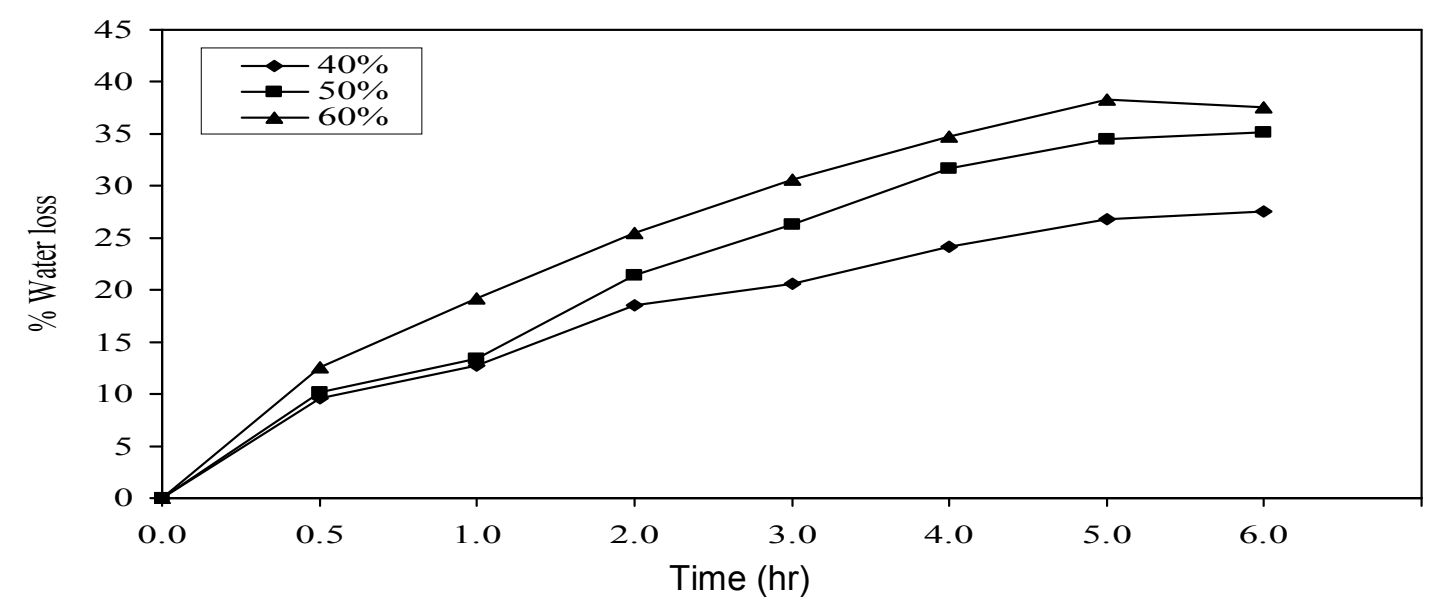

Fig. 1. Influence of different sugar solution concentration at $40^{\circ} \mathrm{C}$ on $\%$ water loss (WL) of pineapple slices of $10 \mathrm{~mm}$ thickness

In the case of sugar uptake, Fig. 2 shows that sugar gain significantly increased $(p=0.05)$ with increasing sugar solution concentration. However, values sugar gain of the fruit obtained by using $40 \%$ sugar solution was not significantly different $(p=0.05)$ from that obtained when $50 \%$ sugar solution was used. This was observed in Figure 2 by the closeness of the two curves depicting changes of sugar gain of pineapple with osmotic time due to the $40 \%$ and $50 \%$ sugar solution concentrations.

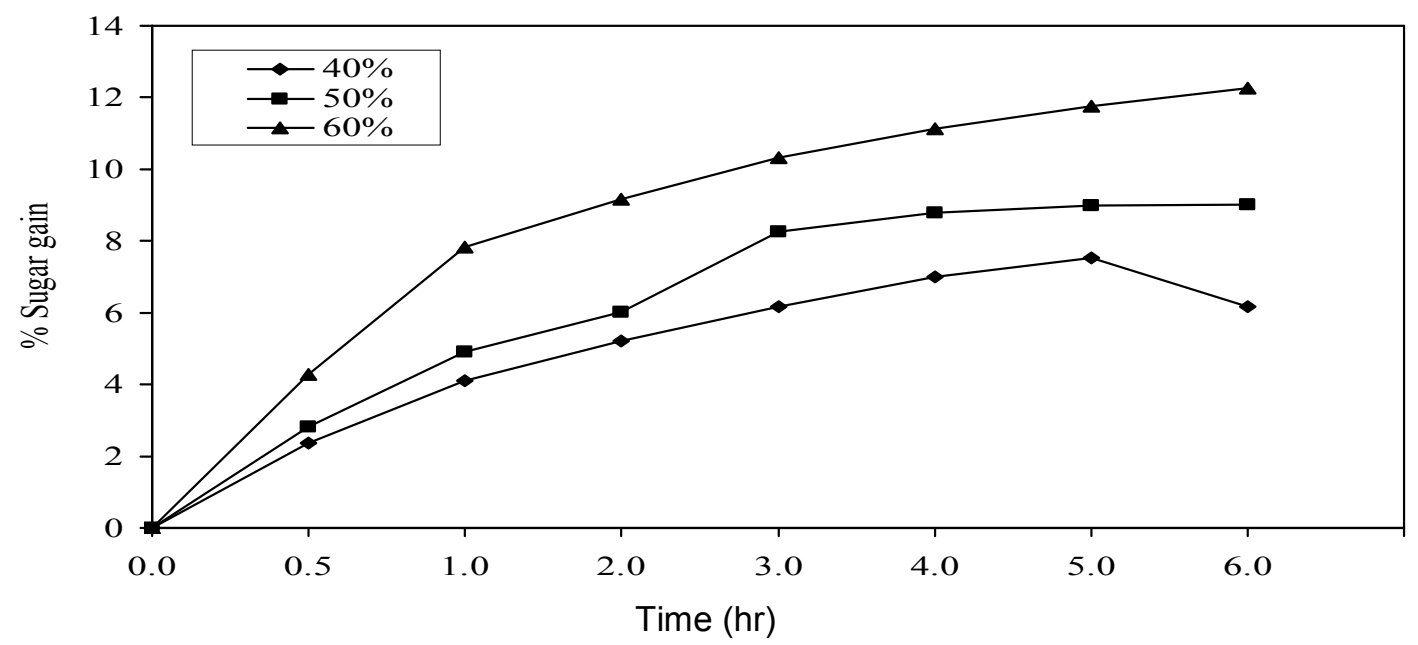

Fig. 2. Influence of different sugar solution concentration at $40^{\circ} \mathrm{C}$ on $\%$ sugar gain (SG) of pineapple slices of $10 \mathrm{~mm}$ thickness 
Fig. 3 shows that increasing the sugar concentration of the osmotic solution from $40 \%$ to $60 \%$ increased the weight reduction values of the osmotically-dried fruit. Ponting et al. (1966) using apples, noticed that at high sugar concentrations (above 65\%) additional increase in concentration did not promote further weight loss. Similar responses to concentration increases were observed by Contreras and Smyrl (1981) although there was a difference regarding the concentration cut point; that is, the point above which an increase in concentration was not followed by a significant increase in weight loss. This difference can be explained on the basis of differences in experimental setup among the above workers (Lazarides, 1994).

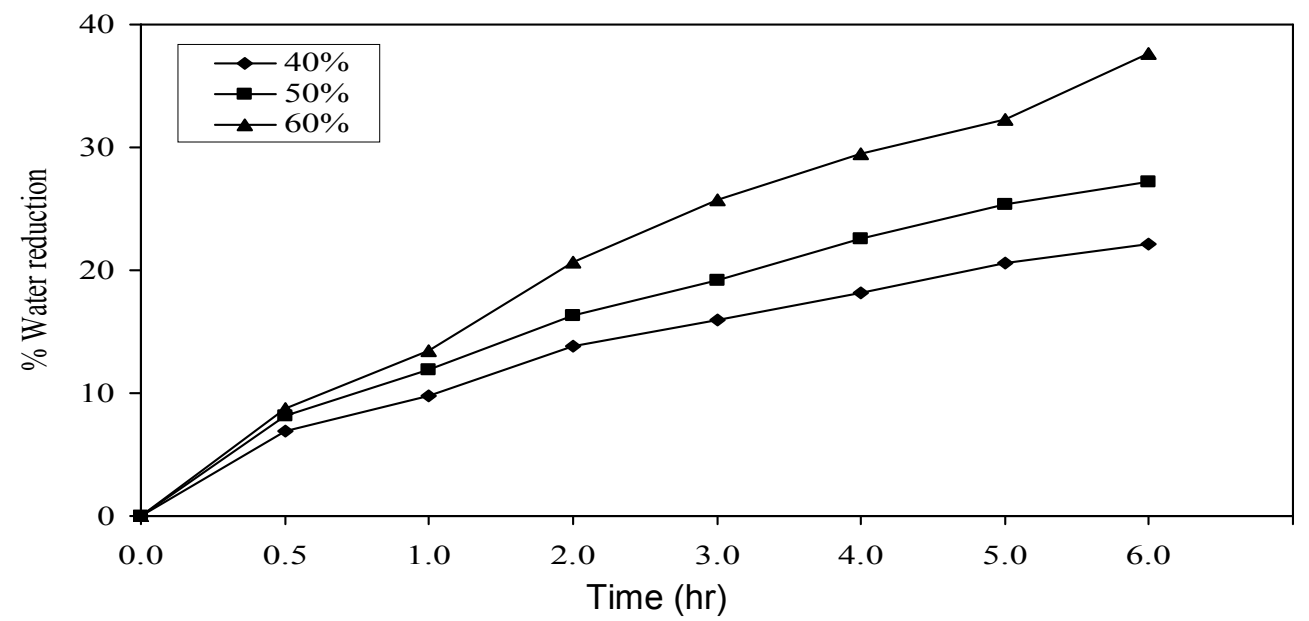

Fig. 3. Influence of different sugar solution concentration at $40^{\circ} \mathrm{C}$ on $\%$ weight reduction (WR) of pineapple slices of $10 \mathrm{~mm}$ thickness

Fig. 4 shows that amount of total solids in the osmosed fruit significantly increased $(p=0.001)$ with increase in sugar solution concentration. Thus, the use of very high sugar solution concentration $(60 \%$ sugar) resulted in higher amount of sugar uptake by the fruit at the expense of lower water loss values as evidence by the low WL/SG ratio and higher TSo /TSi ratio (Normalized Solids content) in Table 1.

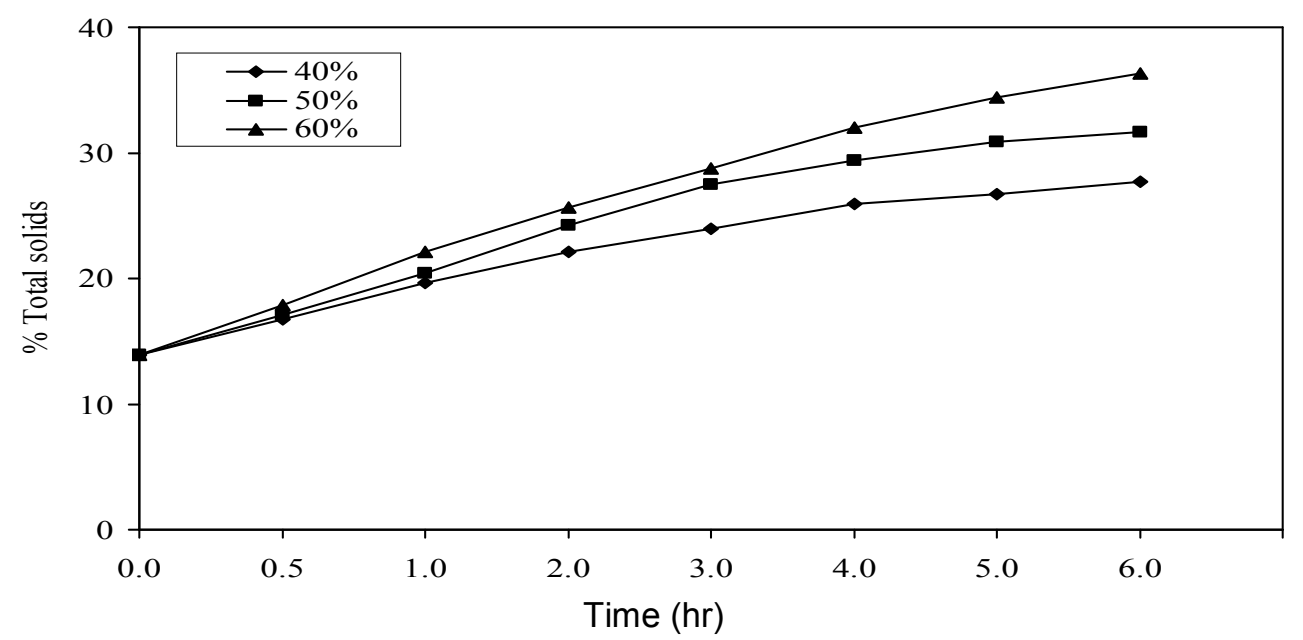

Fig. 4. Influence of different sugar solution concentration at $40^{\circ} \mathrm{C}$ on $\%$ total solids (TS) of pineapple slices of $10 \mathrm{~mm}$ thickness

The higher amount of sugar uptake probably resulted in rapid development of a concentrated sugar layer under the surface of the fruit pieces, upsetting the osmotic pressure gradient across the fruit-sugar solution interface and therefore decreasing the driving force for water flow (Hawkes and Flink, 1978). Hughes et al. (1958) working on the penetration of maltosaccharides in processed Clingstone peaches, reported that the rate of solute penetration was directly related to the solution concentration and inversely 
related to the size of the sugar molecule. At lower concentrations of sugar (40 to 50\% sugar), WL/SG ratios were the highest for the first 30 minutes of osmosis indicating the rate of water loss from the pineapple was the highest during the first half hour of the osmotic process before the ratios began to drop and then increased or decreased slightly with time (Table 1). The TSo/TSi ratio (NSC) of the three sugar solution concentrations studied increased with increase in both sugar concentrations and osmotic time.

Furthermore, the WL/SG and TSo/TSi ratios (Table 1) for the $60 \%$ sugar concentration after 6 hours of osmotic process were 3.79 and 2.73, respectively (second highest in both cases). Sankat (1992) found that in the case of banana slices immersed in $50^{\circ}$ Brix sugar solution for 36 hours, the reduction in weight of the fruit slices was only $24.2 \%$.

Table 1.WL/SG ratio and normalised solids content (NSC) of osmosed pineapple as a function of fruit blanching treatments and osmotic time and sugar solution concentrations

\begin{tabular}{|l|c|c|c|c|c|c|}
\hline \multirow{2}{*}{$\begin{array}{c}\text { Osmotic } \\
\text { time (hours) }\end{array}$} & \multicolumn{3}{|c|}{ WL/SG ratio } & \multicolumn{4}{c|}{ NSC = TSo/TSi } \\
\cline { 2 - 7 } & \multicolumn{2}{|c|}{ Sugar solution concentrations } & \multicolumn{2}{c|}{ Sugar solution concentrations } \\
\cline { 2 - 7 } & $\mathbf{4 0 \%}$ & $\mathbf{5 0 \%}$ & $\mathbf{6 0 \%}$ & $\mathbf{4 0 \%}$ & $\mathbf{5 0 \%}$ & $\mathbf{6 0 \%}$ \\
\hline 0.5 & 4.04 & 3.61 & 2.94 & 1.20 & 1.22 & 1.28 \\
\hline 1.0 & 3.10 & 2.73 & 2.46 & 1.41 & 1.46 & 1.58 \\
\hline 2.0 & 3.55 & 3.55 & 2.78 & 1.59 & 1.74 & 1.84 \\
\hline 3.0 & 3.34 & 3.18 & 2.96 & 1.72 & 1.97 & 2.06 \\
\hline 4.0 & 3.45 & 3.61 & 3.12 & 1.86 & 2.11 & 2.29 \\
\hline 5.0 & 3.56 & 3.84 & 3.26 & 1.91 & 2.21 & 2.47 \\
\hline 6.0 & 3.46 & 3.90 & 3.22 & 1.98 & 2.27 & 2.60 \\
\hline Mean $^{*}$ & 3.5 & 3.48 & 2.96 & 1.66 & 1.85 & 2.01 \\
\hline
\end{tabular}

* Mean of WL/SG ratios determined at seven osmotic time

Several researchers working with other fruits and vegetables (Hawkes and Flink, 1978; Moy et al., 1978; Islam and Flink, 1982; Conway et al., 1983; Lenart and Flink, 1984a and Pavasovic et al., 1986) have also reported increased water loss with increase in osmotic solution concentrations. However, they did not point out the occurrence of reduced WL/SG ratio when high osmotic solution concentration ( $\geq 60 \%$ sugar solution) was used.

Hawkes and Flink (1978) in investigating the mass transport in the osmotic concentration of apples found that the mass transfer coefficient increased with sucrose concentration and was also influenced by agitation when the concentration of the sugar solution was $50 \%$ or greater. It should also be pointed out that, if the levels of sugar uptake into the fruit slices need to be a certain desired level, the sugar solution concentration that can maximize the rates of water loss and weight reduction and at the same time minimize the rate of sugar uptake had to be found.

\section{Conclusion}

- Six hours of osmotic process, using $60 \%$ sugar solution is recommended for the osmotic dehydration of pineapples due to its high rates of water loss (39.56\%) and weight reduction (37.63\%) as compared to those of $50 \%$ sugar solution (35.18\% water loss; $27.18 \%$ weight reduction) and $40 \%$ sugar solution (27.58\% water loss; $22.15 \%$ weight reduction).

- The level of sugar uptake in 6 hours of osmotic process in $60 \%, 50 \%$ and $40 \%$ sugar solutions were $12.26 \%, 9.02 \%$ and $6.18 \%$, respectively. 


\section{References}

Bartolomew, A.P., Pilar, R. and Foster, C. 1995. Pineapple fruit: morphological characteristics, chemical composition and sensory analysis of Red Spanish and Smooth cayennc cultivars. Food Chem., 53: 75-79.

Conway, J., Castaigne, F., Picard, C. and Vovan, X. 1983. Mass transfer considerations in the osmotic dehydration of apples. Can. Inst. Food Sci. Technol. J.vol:25-29.

Brennan, J.G. 1987. Objective evaluation of the quality of the osmosed and post-osmotic processed apples. Unpublished Report.

Contreras, J.E. and T. Smyrl, G. 1981. An evaluation of osmotic concentration of apple rings using com syrup solids solutions. Can. Inst. Food Sci. Technol. J. 14 (4): 310-314.

Gherardi, S., Laratta. B., Loiudice. R., Trifiro. A., Addario. G., Zanotti, A. and Castaldo, D. 1994. Sulla tecnologia di produzione del succo di ananas :composizione del succoetermoresistenza della pectin-metilesterasi, Industria Conserve.69.199-203.

Hawakes, J. and Flink, M.J. 1978. Osmotic concentration of fruit slices prior to freeze-dehydration. J. Food Proc. and Preserv., 2: 265-284.

Hough, G.; Chirife. J. and Marini, C (1993).A simple model for osmotic dehydrationof apples. Lebensmitel-Wissenschaft undTechnolgie.26.151-156.

Islam, M.N. and Flink, M.J. 1982. Dehydration of potato. 11. Osmotic concentration and its effect on air drying behaviour. J. Food Technol, 17: 387-403.

Lazarides, H.N. 1994. Osmotic preconcentration- developments and prospects. In: Minimal Processing of Foods and Process Optimization - An Interface. R. Paul Singh and F.A.R. Oliveira (Eds.), CRC Press, London, pp. 73-85.

Lenart, A. and Flink, M.J. 1984. Osmotic concentration of potato. II. Spatial distribution of the osmotic effect. J. Food Technol, 19: 65-89.

Lenart, A. and Flink, M.J. 1984a. Osmotic concentration of potato. 1. Criteria for the end-point of the osmotic process. J. Food Technol, 19: 45-63.

Ponting, J.D., Watters, G.G., Forrey, R.R., Jackson, R. and W.L. Stanley. 1966. Osmotic dehydration of fruits. Food Technol, 20 (10): 125-128.

Raoult Wack, A; Rios. G; Saurei. R;G; Saurel. R; Giroux. F. and Guilbert. S. 1994. Modeling of dewatering and impregnation soaking process (osmotic dehydration). Food R. Int., 27: 207-209.

Sankart, C.K. and Castaigne, F. 1992. Banana dehydration: osmotic, air and solar effects. In: Drying '92. A.S. Mujumdar (Ed.), Elsevier Science Publishers, pp. 1679-1687.

Spiazzi, E. and Mascheronl, R.H. 1997. Mass transfer model for osmotic dehydration of fruits and vegetables- I. Development of the Simulation Model. J. Food Eng., 34: 387-410. 